\title{
A TIPIFICAÇÃO DA VIOLÊNCIA CONTRA A MULHER NO MUNICÍPIO DE
} JUAZEIRO/BA

VIOLENCE TYPIFING AGAINST WOMEN IN THE MUNICIPALITY OF JUAZEIRO/BA

\author{
Luana Nunes Cabral \\ Estudante de Direito - UNEB \\ luana.nunescabral@gmail.com
}

\author{
Anna Christina Freire Barbosa \\ Doutora em Ciências Sociais \\ Professora na UNEB e da Faculdade de Ciências Aplicadas e Sociais de Petrolina/PE \\ acbarbosa@uneb.br
}

\section{Resumo}

O contexto social marcado pela desigualdade de gênero, cuja supremacia masculina justifica a subjugação feminina, encontra na violência contra a mulher um dispositivo mantenedor desse fenômeno. $O$ trabalho objetiva analisar os tipos de violência mais recorrentes em Juazeiro/BA, detectados pelo Centro Integrado de Atendimento à Mulher (CIAM), através da classificação da Lei $n^{\circ} 11.340 / 06$. Visa também traçar o perfil socioeconômico das assistidas e discutir a efetividade das políticas públicas nesse cenário, a partir dos dados sobre reincidência. A abordagem metodológica adotada é qualiquantitativa dos registros de atendimentos realizados entre os anos de 2006 e 2018. A análise compreende o levantamento anual sistematizado pelo centro e cinco fichas cadastrais de mulheres que procuraram o CIAM em 2017 e 2018. Os resultados apontam a violência psicológica como a de maior incidência no período, registrando $41,29 \%$ dos 2.143 casos notificados. Observa-se um perfil assinalado por mulheres entre 22 e 49 anos, que concluíram o ensino médio, desempregadas, com renda familiar entre um e dois salários mínimos, apontando o agressor como provedor da casa e com tempo de convivência superior a 10 anos. No tocante à efetividade das políticas públicas, em 2015 registraram-se 281 casos, dos quais $33,8 \%$ foram recidivas. Os dados indicam um processo de desnaturalização da violência, notadamente em sua vertente psicológica, evocando o poder público para o desenvolvimento de mecanismos de enfrentamento mais consentâneos com o perfil caracterizado. Problematizase a debilidade da rede de assistência frente ao percentual de mulheres vitimadas de forma reincidente, demandando uma atuação estatal mais holística.

Palavras-chave: Gênero. Desigualdades. Políticas públicas. Mulher. Violência.

\section{Abstract}

The social context marked by gender inequality, whose male supremacy justifies female subjugation, finds in violence against women a device sustaining this phenomenon. The study aims to analyze the most recurrent types of violence in Juazeiro/BA, detected by the Center for Integrated Care for Women (CIAM), through the classification of Law 11.340/06. It also aims to outline the socioeconomic profile of those assisted and discuss the effectiveness of public policies in this scenario, based on data on recidivism. The methodological approach adopted is qualitative quantitative of the records of care performed between 2006 and 2018. The analysis comprises the annual survey systematized by the center and five registration 
forms of women who sought CIAM in 2017 e 2018. The results indicate psychological violence as the one with the highest incidence in the period, recording $41.29 \%$ of the 2,143 reported cases. A profile pointed out by women between 22 and 49 years of age, who completed high school, unemployed, with family income between one and two minimum wages, pointing the aggressor as a provider of the house and with more than 10 years of coexistence. Regarding the effectiveness of public policies, in 2015 there were 281 cases, of which $33.8 \%$ were recurrences. The data indicate a process of denaturalization of violence, notably in its psychological aspect, evoking the public power for the development of coping mechanisms more in line with the characterized profile. The weakness of the care network in relation to the percentage of women victimized by recurrence is problematized, requiring a more holistic state action.

Keywords: Gender. Inequalities. Public policy. Woman. Violence.

\section{INTRODUÇÃO}

A violência contra mulher é um fenômeno social que se reveste de formas diversas, desdobrando-se, de modo geral, em cinco vertentes: física, patrimonial, sexual, moral e psicológica. Esta, por sua vez, caracteriza-se de modo singular, vez que costuma estar presente em todas as formas de violência, provocando em suas vítimas sofrimentos diversos.

Tal fenômeno se expressa em razão do machismo estrutural que subsiste em todas as esferas da vida em sociedade, respaldando a violência como instrumento hábil à garantia da dominação do homem sobre a mulher no exercício da função patriarcal.

Nesse contexto surge o Centro Integrado de Atendimento à Mulher de Juazeiro/BA (CIAM), como veículo indispensável ao combate da violência contra mulher no município, viabilizando políticas multidisciplinares de enfrentamento e ressignificação desse fenômeno social, integrado à Rede Municipal de Assistência Social e Combate à Violência de Gênero e Desigualdade Social.

Para compreender o escopo da atuação daquela instituição este trabalho visou tipificar os registros de violência no município de Juazeiro/BA, a partir dos registros primários do CIAM, bem como, traçou o perfil socioeconômico das assistidas, vislumbrando os marcadores sociais pertinentes; e, por fim, analisou a efetividade das políticas públicas no combate a essa forma de violência. Destarte, tomou por base bibliografia pertinente à violência de gênero, a fim de debater os resultados obtidos e fortalecer os mecanismos de enfrentamento existentes.

Para fins didáticos, além desta introdução, esse estudo apresenta-se em três seções, quais sejam: na segunda especifica a metodologia empregada; na terceira apresenta e analisa a violência contra mulher, desigualdade de gênero e contexto juazeirense, com dados relativos à tipificação da violência, perfil socioeconômico do público atendido e discussão relativa afetividade das políticas públicas ofertadas; por fim, a seção quatro traz as considerações finais.

\section{METODOLOGIA}

A pesquisa tomou por base o banco de dados disponível no CIAM, a partir de uma abordagem qualiquantitativa. Esses dados primários compreendem o levantamento anual sistematizado pelos profissionais do centro e cinco fichas cadastrais de mulheres que procuraram o CIAM em busca de assistência em 2017 e 2018.

No primeiro caso, foram encontrados registros de violência de 2006 a julho de 2018, havendo lacuna entre os anos de 2008 a 2010. Quanto às fichas cadastrais, buscaram-se aleatoriamente cinco casos em 2017 e cinco em 2018, a fim de analisar mais profundamente aspectos não delineados nos primeiros dados, sobretudo, no que concerne ao perfil socioeconômico. O exame desse perfil também ficou restrito aos anos de 2017 e 2018, haja vista disponibilizarem mais informações acerca dessas mulheres e serem mais recentes.

A evolução de caso, isto é, a investigação das mulheres que já estiveram em situação de violência e voltaram a procurar o equipamento, restringiu-se aos anos de 2015 a 2018, visto 
possuírem registros mais precisos acerca da recidiva. Dessa forma, todas as análises deste trabalho se limitam à disponibilidade de dados encontrada no momento da coleta.

\section{VIOLÊNCIA CONTRA MULHER, DESIGUALDADE DE GÊNERO E CONTEXTO JUAZEIRENSE}

A estrutura social legitima relações desiguais de gênero que acabam servindo de alicerce à violência contra mulher, não só ao conferir posições desiguais aos atores sociais - usualmente atribuindo lugares subalternos à figura feminina - mas também ao validar o discurso da supremacia e dominação masculina. Assim, atua o gênero como "um primeiro modo de dar significado às relações de poder" (SCOTT, 1990 apud SAFFIOTI, 1995, p. 8).

Segundo Carme Alemany (2009, p. 271), em Dicionário Crítico do Feminismo, a violência contra mulher pode ser entendida como:

[...] todos os atos que, por meio de ameaça, coação ou força, lhes infligem, na vida privada ou pública, sofrimentos físicos, sexuais ou psicológicos com a finalidade de intimidá-las, puni-las, humilhá-las, atingi-las na sua integridade física e na sua subjetividade.

Nesses moldes, a violência contra mulher é um fenômeno presente na história da humanidade, cujo fundamento abarca relações díspares de gênero que se expressam por meio da subjugação do feminino ao masculino. Por isso mesmo, a violência contra mulher é entendida como a forma mais evidente de violência de gênero, estando, pois, inclusa nessa definição. Assim, alcança todas as camadas sociais, ao passo que evidencia marcadores sociais específicos, tais como raça e classe.

Essa forma de violência tem uma característica muito peculiar, haja vista o âmbito doméstico deixar de ser entendido, para mulher, como um local de proteção e segurança, passando a um viés de eminente perigo. Tal aspecto traduz um paradoxo, pois ao mesmo tempo em que a socialização feminina se encontra imbuída de suspeitas quanto ao desconhecido, os agressores de mulheres, são, na maioria dos casos, parentes ou pessoas próximas. Assim, embora desde muito pequenas as meninas sejam excluídas do espaço público sob o argumento de que esse seria investido de muito perigo à sua constituição corporal e subjetiva fragilizada - o mito da inocência e passividade da mulher - é no espaço intrafamiliar e privado que ocorrem os mais diversos tipos de atrocidades a esse público. Segundo Saffioti (1995), evoluindo como uma escalada, de agressões verbais, físicas, sexuais a ameaças de morte, chegando, em muitos casos trágicos, ao próprio homicídio.

Outrossim, discutir a ciência jurídica frente à dimensão social proposta é compreender as limitações intrínsecas ao ordenamento brasileiro que, somente em caráter tardio e fruto de pressões internacionais, promulgou a Lei no 11.340 de 2006, mais conhecida como "Lei Maria da Penha". Esta traz em seu bojo discussão pertinente ao tema, criando redes multidisciplinares de assistência à mulher. Consigne-se, todavia, que a referida lei repercutiu pequenas modificações na seara penal, exemplo disso é que somente em 2015, mais uma vez, em decorrência de lutas diversas, passou-se a tipificar figura qualificada do crime de homicídio: o "Feminicídio". Este entendido como crime doloso praticado "contra a mulher por razões da condição de sexo feminino" (art. 121, $\S 2^{\circ}$, VI). Para fins de tipificação como feminicídio, considera-se a violência doméstica e familiar ou quando ocorre menosprezo ou discriminação à condição de mulher.

Essa questão mantém relação direta com o que defende Saffioti (1995, p. 15) ao afirmar que "a ética do direito ostenta, como sói acontecer com a ética do dominador, a ambição da universalidade, mas é incapaz de atentar para a diferenciação de gênero gerada pela cultura falocêntrica". Assim, a ciência jurídica demonstra sua ineficiência frente às questões que envolvem as diferenças de gênero, por conseguinte, responde de modo insatisfatório à problemática da violência que tem como razão tais aspectos socialmente consolidados.

Partindo-se da premissa de que a violência tem alicerce nas relações sociais, é imperioso destacar a necessidade de discutir tal fenômeno, a fim de dissecar as estruturas construídas e disseminadas, em sua maioria, como naturais; inclusive relegando à dominação masculina o sentido de ser, por si mesma, uma realidade intrínseca ao humano em razão da disposição 
biologicamente fragilizada da mulher. Por meio do reconhecimento dessa lógica histórica e social tornar-se-á crível desconstruir os fundamentos sobre os quais está enraizada a cultura do abuso ao feminino, em todas as suas vertentes adoecedoras e, consequentemente, proceder à desconstituição da própria violência.

Com efeito, em "A dominação masculina", Pierre Bourdieu (2002) alude à imprescindibilidade de questionar quais os organismos históricos que são responsáveis pela deshistoricização e pela eternização desses mecanismos, inclusive, de divisão sexual. A sua tese mostra-se ímpar, uma vez que amplia a compreensão da violência para além da tradicional concepção que a restringe aos meios visíveis no mundo físico, para discuti-la enquanto meio simbólico de conformação dos corpos.

Diante de tal contexto envolvendo a violência de gênero, destaca-se a Bahia como o segundo estado que mais mata mulheres no Brasil, com base no Atlas da Violência 2018, produzido pelo Instituto de Pesquisa Econômica Aplicada (IPEA) e pelo Fórum Brasileiro de Segurança Pública (FBSP). Ocorreram 441 casos em 2016, o que equivale a 5,7 mulheres assassinadas a cada 100 mil habitantes do estado (CERQUEIRA, 2018). Somente no primeiro semestre de 2018 a Central de Atendimento à Mulher em Situação de Violência registrou 73 mil casos de agressões. Dentre essas estão: cárcere privado, violência física, psicológica, obstétrica, sexual, moral, patrimonial, tráfico de pessoas, homicídio e assédio no esporte (BRITO, 2018).

Ainda segundo levantamento da Secretaria de Segurança Pública da Bahia, o número de feminicídios no estado cresceu 6,1 \% em 2018, em comparação a 2017 (NÚMERO..., 2018). Dados de 2019 apontam que somente nos primeiros 95 dias, as duas Delegacias Especializadas da capital registraram 3.020 casos de agressão, o que equivale a 1,3 mulheres agredidas por hora em Salvador (TODOS..., 2019). Em âmbito internacional, o Brasil ocupa a $5^{\circ}$ posição dentre 83 países onde mais se matam mulheres, conforme Mapa da Violência de 2015 (WAISELFISZ, 2015).

No submédio do Vale do São Francisco, Juazeiro, município baiano localizado ao norte do estado, com pouco mais de 215 mil habitantes, vem consolidando equipamentos primordiais à reconfiguração dessa realidade hostil para as mulheres, não somente visando a punição dos autores, mas, principalmente, viabilizando políticas educacionais voltadas à igualdade de gênero.

Nesse cenário de enfrentamento à violência contra mulher em Juazeiro, foi fundado em 2004 o Centro Integrado de Atendimento à Mulher, órgão vinculado à Secretaria de Desenvolvimento e Igualdade Social (SEDIS) do município, cuja finalidade é "realizar atendimentos de natureza da assistência social, psicológica e jurídica, e se insere no contexto local em parceria com as demais instâncias institucionais dedicadas à mulher e ao adolescente." (BARBOSA, 2014, p. 82).

Embora existente antes da própria Lei Maria da Penha, a partir de 2006 passa a ter um maior protagonismo, com quadro de profissionais da Psicologia, Serviço Social e do Direito. Além de realizar atendimento integrado às assistidas, disponibiliza encaminhamento às demais instâncias competentes, a exemplo da Delegacia Especializada de Atendimento à Mulher (DEAM), bem como, mobiliza instrumentos de empoderamento, realizando oficinas de capacitação profissional, grupos de apoio e palestras. Assim, desde 2006 dispõe de registros dos atendimentos realizados às vítimas de violência, não somente quanto à forma, mas também buscando traçar as características socioeconômicas desse público.

Nesse sentido, o centro atua buscando garantir que as mulheres juazeirenses vítimas de violência possam ressignificar suas histórias, oferecendo-lhes oportunidades reais de saírem do ciclo de violência, tanto através do atendimento interdisciplinar, quanto da profissionalização e força coletiva. Além disso, visa também prevenir que novas mulheres sejam vitimadas, por meio de palestras educacionais que desmistificam os padrões de gênero e a suposta supremacia masculina que objetifica a mulher.

\subsection{TIPIFICAÇÃO DA VIOLÊNCIA}

Destarte, da análise do levantamento anual, foram encontrados entre 2006 e julho de 2018, 2.143 casos de violência contra mulher, salientando-se que esse número não corresponde, necessariamente, ao quantitativo de mulheres atendidas, visto que, uma mulher pode ter sido vítima de mais de um tipo de violência. O perfil concentra-se na classificação feita pelo CIAM, 
que inclui violência psicológica, física, sexual, moral, patrimonial, ameaça e outros. A última categoria refere-se a situações violentas não abarcadas na classificação anterior. Ressalte-se que nem todos os anos apresentam classificação que inclua a tipificação completa (Gráfico 1).

Gráfico 1- Tipificação da violência registrada no CIAM

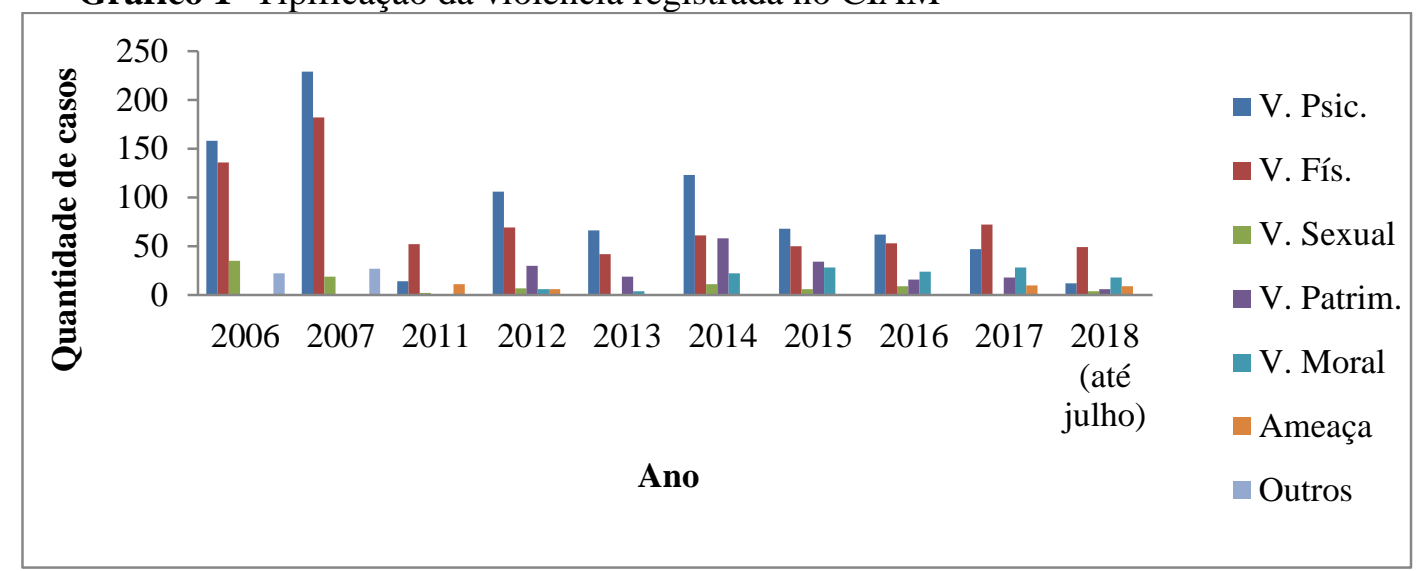

Fonte: CIAM 2006 a julho 2018

Em termos percentuais, tem-se que entre 2006 e julho de 2018, dos 2.143 registros de violência no CIAM (Gráfico 2).

Gráfico 2 - Tipificação da violência registrada no CIAM (\%)

\begin{tabular}{|ccccccc|}
\hline $41,29 \%$ & $35,74 \%$ & & & & \\
& & $4,43 \%$ & $8,44 \%$ & $6,06 \%$ & $1,72 \%$ & $2,28 \%$ \\
\hline V. Psicológica & V. Física & V. Sexual & V. Patrimonial & V. Moral & Ameaça & Outros \\
\hline
\end{tabular}

Fonte: CIAM 2006 a julho 2018

Extrai-se dos gráficos acima que a violência psicológica foi a mais notificada no município, ficando em segundo lugar a física, seguida da patrimonial, moral e sexual. Ameaça e outros somam aproximadamente $4 \%$ do total.

No que tange à investigação pormenorizada, tem-se o Quadro 1 e a Tabela 1:

Quadro 1 - Registros de violência por ano

\begin{tabular}{|lc|}
\hline ANO & N $^{\circ}$ REGISTROS \\
\hline $\mathbf{2 0 0 6}$ & $\mathbf{3 5 1}$ \\
\hline $\mathbf{2 0 0 7}$ & $\mathbf{4 5 7}$ \\
\hline $\mathbf{2 0 1 1}$ & $\mathbf{7 9}$ \\
\hline $\mathbf{2 0 1 2}$ & $\mathbf{2 2 4}$ \\
\hline $\mathbf{2 0 1 3}$ & $\mathbf{1 3 2}$ \\
\hline $\mathbf{2 0 1 4}$ & $\mathbf{2 7 6}$ \\
\hline $\mathbf{2 0 1 5}$ & $\mathbf{1 8 6}$ \\
\hline $\mathbf{2 0 1 6}$ & $\mathbf{1 6 4}$ \\
\hline $\mathbf{2 0 1 7}$ & $\mathbf{1 7 6}$ \\
\hline $\mathbf{2 0 1 8}$ & $\mathbf{9 8}$ \\
\hline Total & $\mathbf{2 . 1 4 3}$ \\
\hline & Elaboração própria \\
\hline Fonte: CIAM 2006 a julho 2018 \\
\hline
\end{tabular}


Tabela 1 - Tipificação da violência registrada no CIAM por ano (\%)

\begin{tabular}{|lllllllll} 
Ano & $\begin{array}{c}\text { Violência } \\
\text { Psicológica }\end{array}$ & $\begin{array}{c}\text { Violência } \\
\text { Física }\end{array}$ & $\begin{array}{c}\text { Violência } \\
\text { Sexual }\end{array}$ & $\begin{array}{c}\text { Violência } \\
\text { Patrimonial }\end{array}$ & $\begin{array}{c}\text { Violência } \\
\text { Moral }\end{array}$ & Ameaça & Outros & Total \\
$\mathbf{2 0 0 6}$ & $45,01 \%$ & $38,74 \%$ & $9,98 \%$ & - & - & - & $6,27 \%$ & $100 \%$ \\
$\mathbf{2 0 0 7}$ & $50,11 \%$ & $39,82 \%$ & $4,16 \%$ & - & - & - & $5,91 \%$ & $100 \%$ \\
$\mathbf{2 0 1 1}$ & $17,72 \%$ & $65,82 \%$ & $2,54 \%$ & - & - & $13,92 \%$ & - & $100 \%$ \\
$\mathbf{2 0 1 2}$ & $47,32 \%$ & $30,81 \%$ & $3,12 \%$ & $13,40 \%$ & $2,67 \%$ & $2,68 \%$ & - & $100 \%$ \\
$\mathbf{2 0 1 3}$ & $50,01 \%$ & $31,81 \%$ & $0,75 \%$ & $14,40 \%$ & $3,03 \%$ & - & - & $100 \%$ \\
$\mathbf{2 0 1 4}$ & $44,56 \%$ & $22,10 \%$ & $3,99 \%$ & $21,01 \%$ & $7,98 \%$ & $0,36 \%$ & - & $100 \%$ \\
$\mathbf{2 0 1 5}$ & $36,55 \%$ & $26,89 \%$ & $3,22 \%$ & $18,28 \%$ & $15,06 \%$ & - & - & $100 \%$ \\
$\mathbf{2 0 1 6}$ & $37,81 \%$ & $32,31 \%$ & $5,49 \%$ & $9,76 \%$ & $14,63 \%$ & - & - & $100 \%$ \\
$\mathbf{2 0 1 7}$ & $26,71 \%$ & $40,91 \%$ & $0,57 \%$ & $10,22 \%$ & $15,90 \%$ & $5,69 \%$ & - & $100 \%$ \\
\hline $\mathbf{2 0 1 8}$ & $12,24 \%$ & $50,00 \%$ & $4,08 \%$ & $6,12 \%$ & $18,37 \%$ & $9,19 \%$ & - & $100 \%$
\end{tabular}

Fonte: Elaboração própria

Dados: CIAM 2006 a julho 2018

Infere-se, com exceção dos anos de 2011, 2017 e 2018, que possuem mais registros de violência física, que a violência psicológica é a mais expressiva nos demais períodos.

Deveras, é imperioso destacar o que vem a ser cada modalidade descrita. Partindo do artigo $7^{\circ}$ da Lei $\mathrm{n}^{\circ} 11.340 / 2006$, para efeitos de tipificar a violência doméstica e familiar contra mulher, considera a violência física, psicológica, sexual, patrimonial e moral, como formas de sua expressão.

Violência física corresponde às condutas que ofendam a integridade corporal da mulher. Psicológica é a violência que envolve qualquer conduta capaz de causar dano emocional, diminuição da autoestima, que prejudique o pleno desenvolvimento, ou que intente degradar ou mesmo controlar as ações e crenças da vítima, mediante ameaça, constrangimento, humilhação, manipulação, isolamento, vigilância constante, perseguição contumaz, insulto, dentre outros que venham a causar prejuízos à saúde psicológica e à autodeterminação da vítima.

Violência sexual, por sua vez, é definida como qualquer conduta que constranja a mulher a presenciar, manter ou participar de relação sexual não desejada, mediante intimidação, ameaça, coação ou uso da força; que a induza a comercializar sua sexualidade, que a impeça de usar métodos contraceptivos, ou a force ao matrimônio, gravidez, aborto, prostituição, por coação, suborno, manipulação, chantagem, ou atue limitando ou anulando o exercício dos seus direitos sexuais e reprodutivos.

A violência patrimonial envolve retenção, subtração, destruição parcial ou total de seus objetos, instrumentos de trabalho, documentos pessoais, bens, valores e direitos econômicos, incluindo os destinados a satisfazer suas necessidades. Por fim, para efeitos de conceituação, a lei define violência moral como conduta que configure calúnia, difamação ou injúria, que são espécies de crimes contra honra.

Constata-se que, muito embora para fins de tipificação o CIAM utilize a ameaça de modo separado às formas de violência, o diploma legal a insere como uma espécie de meio capaz de perpetuar essas modalidades de violência. Desse modo, tais registros de ameaça aludem aos apontamentos de Saffioti (1995), ao afirmar que a alta frequência do crime de ameaça atua como mantenedor do status quo de gênero. Sendo assim, muitos homens utilizam desse crime como mecanismo de coação moral, exercendo sobre essas mulheres o poder de conformação de suas condutas, a fim de enaltecer sua suposta supremacia decorrente do gênero.

Por outro lado, a violência psicológica, ainda que referida no presente estudo de maneira mais expressiva, sendo a mais notificada, tende a ser considerada a categoria mais negligenciada de violência doméstica contra mulher (SILVA; COELHO; CAPONI; 2007). Isso ocorre porque sua expressão é comumente naturalizada pela vítima, que, por vezes, justifica esses episódios através de outras contingências, o que silencia o problema. Muitas mulheres, fragilizadas pelo estado de violência, acabam fingindo sua não ocorrência. Para Silva, Coelho e Caponi (2007), é característico dessa forma de violência que a vítima internalize o discurso adoecedor do parceiro, o que atua como agravante, diminuindo sua autoestima. 
Nessa toada, destacou-se com mais veemência neste trabalho a violência psicológica, especialmente pelo fato de que atua como embrião em todas as formas de violência. Sutil e perversamente vai se inserindo na psiqué da vítima, impedindo-a de buscar assistência.

De fato, a própria mídia tende a expor apenas os dados relativos à violência física, dando prevalência, muitas vezes à urbana, ao mesmo tempo em que os institutos oficiais dão primazia às tipificações voltadas a essa categoria. Inclusive, ao buscar pesquisas e materiais que discutam o tema, pouco arcabouço teórico costuma ser encontrado. fenômeno:

Referindo-se à problemática, trazem ponderação interessante para discussão do

\begin{abstract}
Para as mulheres, o pior da violência psicológica não é a violência em si, mas a tortura mental e convivência com o medo e terror. Por isso, este tipo de violência deve ser analisado como um grave problema de saúde pública e, como tal, merece espaço de discussão, ampliação da prevenção e criação de políticas públicas específicas para o seu enfrentamento (SILVA; COELHO; CAPONI, 2007, p. 99).
\end{abstract}

Ao aludir à necessidade de tratar tal violência como efetivamente uma questão de saúde pública, sensibiliza o sistema a atribuir a importância devida à discussão e consequente embate à violência psicológica. Isso se mostra imprescindível tendo em vista que essa forma de violência, de forma perspicaz, repercute consequências não só para vítima, vez que também pode atingir os filhos que presenciam a situação violenta. Estes, por sua vez, podem vir a repetir o comportamento agressivo, tornando-se adultos violentos.

Como já mencionado, a violência psicológica se apresenta imbricada a outras formas de violência, sendo, em muitos casos, sua mola propulsora. Por isso mesmo, combatê-la pode significar a superação das demais expressões de violência, valendo o alerta para as instâncias públicas de modo geral. Assim:

[...] há a necessidade de uma compreensão de que a violência psicológica, caso seja contida, possa servir como estratégia de redução das demais violências. Da mesma forma, a prevenção da violência psicológica pode ser pensada como uma estratégia de prevenção da violência de modo geral, isto é, não só da violência familiar, mas também da institucional e social (SILVA; COELHO; CAPONI, 2007, p. 102).

Oportuno reconhecer que o fato de que o CIAM dispõe de tipificações que abarcam a violência psicológica e, sobretudo, as assistidas se reconhecerem enquanto vítimas dessa forma de agressão, revela-se um fator favorável à tomada de consciência dessas mulheres como consequência da desnaturalização do fenômeno. Inclusive, quanto aos meios de enfrentamento e políticas públicas específicas voltadas a essa vertente de violência contra mulher.

\title{
3.2 PERFIL SOCIOECONÔMICO
}

Outrossim, na tentativa de compreender quais os marcadores sociais evidenciados no perfil da violência contra mulher no município, foram examinados os registros dos anos de 2017 e 2018, os quais abrangem: faixa-etária, raça/cor, escolaridade, religião, profissão, renda familiar, provedor da casa, se recebiam benefício social, tempo de convivência, tipo de moradia, se prestaram queixa e se requereram medida protetiva. A comparação entre os anos de 2017 e 2018 ocorre apenas nos marcadores: faixa-etária, raça/cor e escolaridade. Isso porque, em função das limitações metodológicas, são os únicos que aparecem em ambos os períodos. Os demais aspectos do perfil socioeconômico referem-se a 2018. 


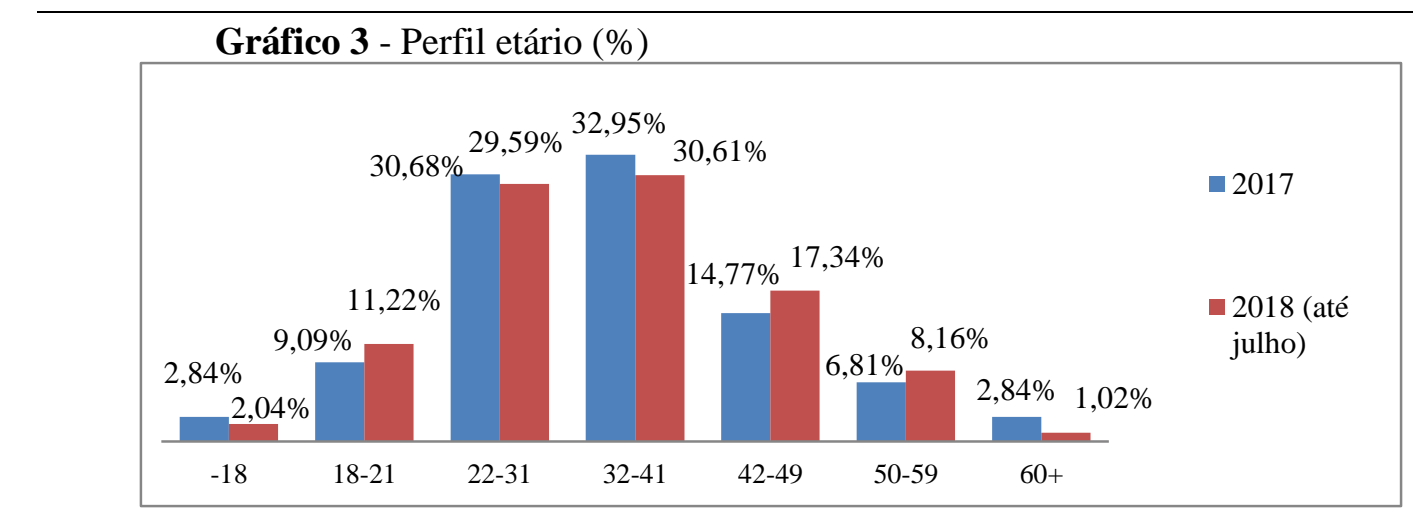

Fonte: Elaboração própria

Dados: CIAM 2017 a julho 2018

Gráfico 4 - Perfil educacional (\%)

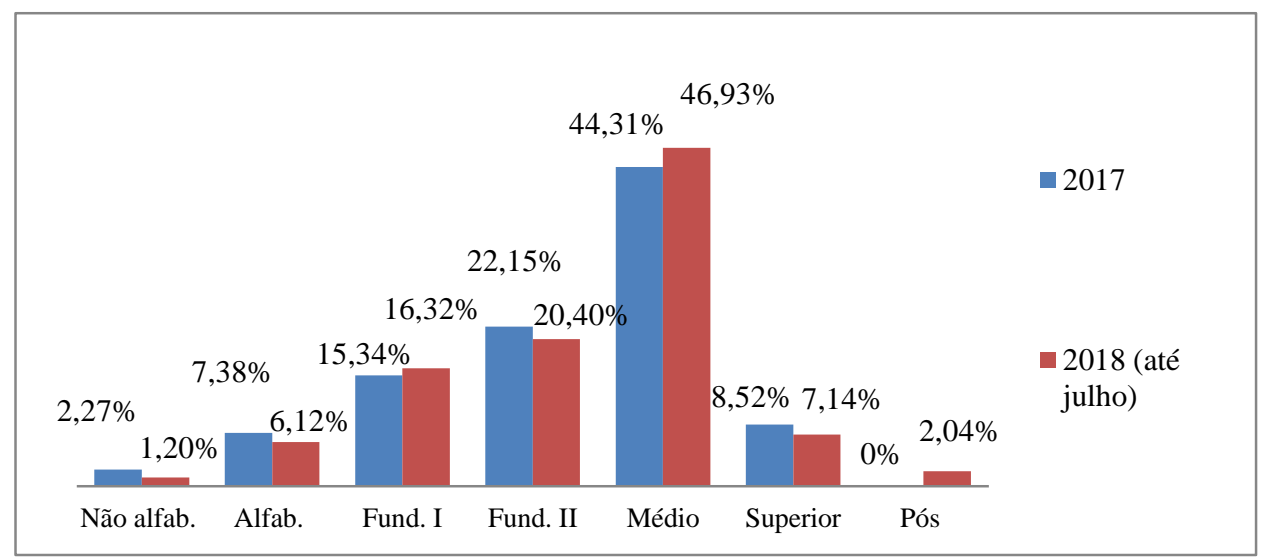

Fonte: Elaboração própria

Dados: CIAM 2017 a julho 2018

Gráfico 5 - Perfil racial (\%)

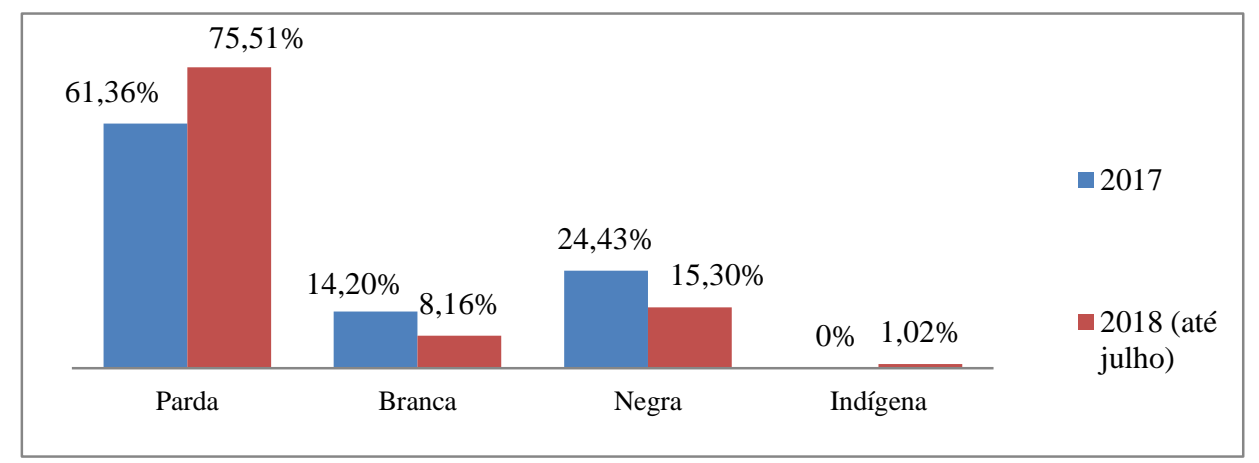

Fonte: Elaboração própria

Dados: CIAM 2017 a julho 2018

Dos Gráficos 3, 4 e 5 percebe-se em 2017 e 2018 um padrão semelhante quanto às caraterísticas mais expressivas nos marcadores sociais. Sendo assim, tem-se o perfil etário mais vitimado pela violência no CIAM de 32 a 41 anos, correspondendo a 32,95\% dos casos registrados em 2017 e 30,61\% de 2018. Com percentuais aproximados, a faixa de 22 a 31 anos também se destaca. Acerca do nível de escolaridade das vítimas, aparecem em destaque as mulheres com ensino médio completo, 44,31\% e 46,93\%, respectivamente, 2017 e 2018, seguidas por aquelas que completaram o fundamental II. As mulheres não alfabetizadas representam os percentuais mais inferiores, $2,27 \%$ e 1,20\%, ficando acima apenas das que fizeram pós-graduação, $2,04 \%$, este, por sua vez, aparece somente em 2018. Quanto ao perfil racial, as mulheres pardas 
surgem em primeiro lugar, com 61,36\% em 2017 e 75,51\% em 2018; seguidas das negras, brancas e indígenas. Este último dado consta unicamente em 2018.

A princípio, vale ressaltar a necessidade de observação dos dados aqui descritos com ponderação, considerando que, não obstante representem um recorte do fenômeno juazeirense, não necessariamente correspondem com precisão à realidade cotidiana da violência contra mulher. Mormente se considerada a subnotificação evidenciada em grande parte dos casos relativos a essa forma de violência. Assim, por múltiplos fatores envolvendo desde a ordem psicológica à econômica, muitas vítimas de violência não conseguem expressar suas dores ou gritar por socorro. São esses casos que nunca chegam a centros ou delegacias especializadas, dissipando-se sem que alcancem qualquer quantificação oficial.

Ao estudar o perfil descrito, vê-se que as mulheres com ensino médio foram as que mais procuraram o centro, correspondendo a quase $50 \%$ do público assistido em ambos os períodos. Diante disso é possível inferir que o acesso à informação revela-se um poderoso divisor de águas no reconhecimento e combate à violência, assim como ficou constatado no estudo realizado por Cortês, Luciano e Dias (2012, p.148):

\begin{abstract}
A informação é fator impulsionador no processo de tomada de decisões e no planejamento e controle social de políticas públicas. Uma ferramenta imprescindível para se fortalecer o monitoramento e aprimorar ações que visam alterar a desigualdade que afeta a vida de milhares de mulheres cotidianamente em decorrência de padrões hierárquicos de gênero.
\end{abstract}

Por sua vez, o trabalho realizado por Mota, Vasconcelos e Assis (2007, p. 807) com mulheres em situação de violência doméstica constatou que:

[...] as agressões físicas mais graves associadas às mulheres com maior escolaridade podem ter sido desencadeadas pelo fato das mesmas não terem aceitado a violência e revidar a agressão, gerando um conflito de maiores proporções e agressões físicas mais graves.

Nessa acepção, mulheres não alfabetizadas ou com pouca instrução formal representaram menor índice, o que pode corroborar tal compreensão. No entanto, observou-se que as mulheres dotadas de instrução superior também representaram baixo percentual, o que pode evidenciar tão somente que o centro não tende a ser objeto de procura desse perfil de mulheres vítimas de violência e não, necessariamente, que tal público seja menos acometido pelo fenômeno. Para chegar a tal conclusão, basta imaginar que, em regra, essas mulheres dispõem de maior poder econômico, podendo acessar serviços psicológicos e jurídicos privados, dispensando assistência gratuita.

No que concerne ao perfil racial, mais da metade das vítimas se autodeclararam pardas. Isso pode colaborar para percepção de que muitas mulheres não possuem consciência de sua própria cor, fruto, especialmente, do racismo estrutural que subsiste em todas as esferas da vida em sociedade, revelando tendência à categorização como pardas.

Dessa forma, pardas e pretas corresponderam ao perfil que mais acessou o CIAM em 2017 e 2018, denotando a vulnerabilidade social desse público e a importância de criação de veículos de enfrentamento mais consentâneos com essa realidade. Inclusive, sem homogeneizar o estudo da violência contra mulher a fim de combatê-la de maneira mais efetiva.

Passaremos agora para apreciação do perfil socioeconômico remanescente, categorizado apenas em 2018, até o mês de julho. 
Gráfico 6 - Perfil religioso (\%)

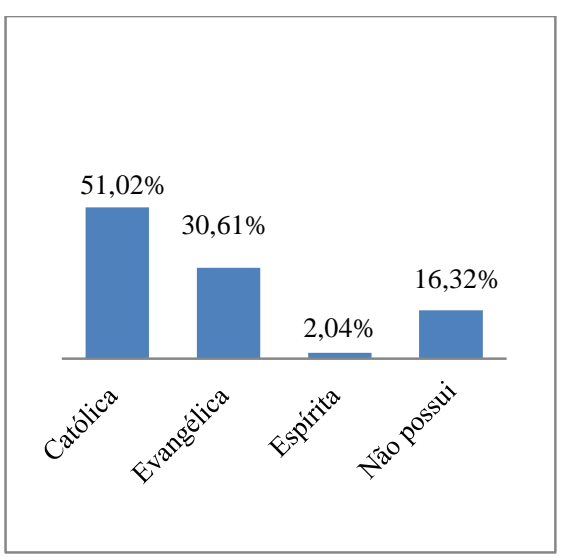

Fonte: Elaboração própria

Dados: CIAM 2018
Gráfico 7 - Perfil profissional (\%)

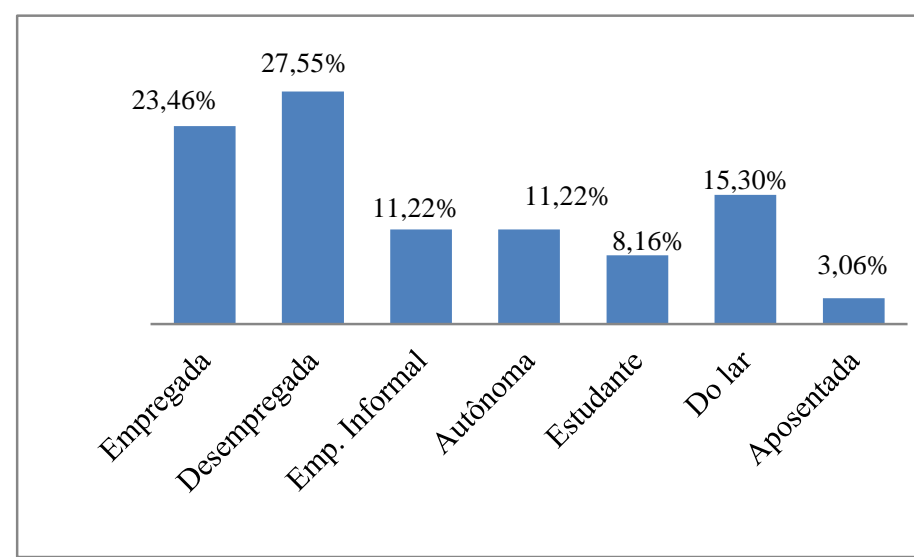

Fonte: Elaboração própria

Dados: CIAM 2018
Gráfico 8 - Renda familiar (\%)

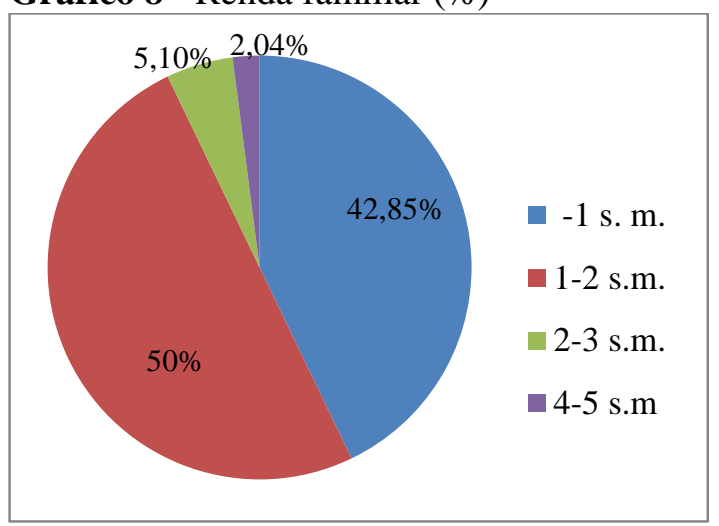

S.m = salário mínimo

Fonte: Elaboração própria

Dados: CIAM 2018
Gráfico 9 - Provedor da casa (\%)

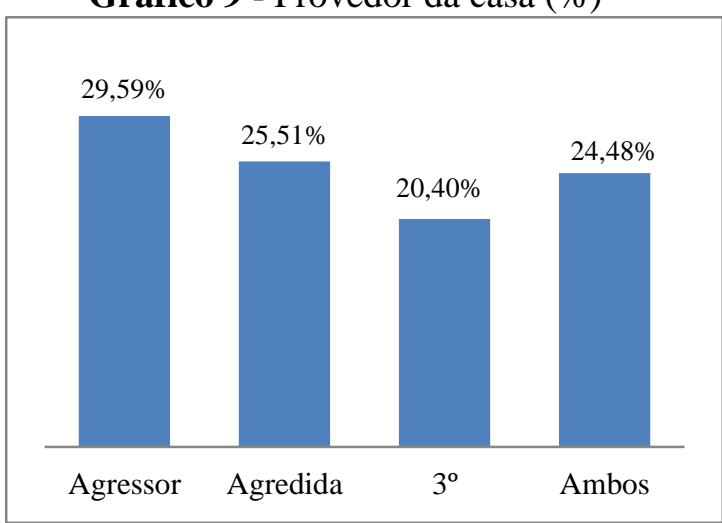

Fonte: Elaboração própria Dados: CIAM 2018

Gráfico 10 - Beneficiárias de auxílio social (\%)

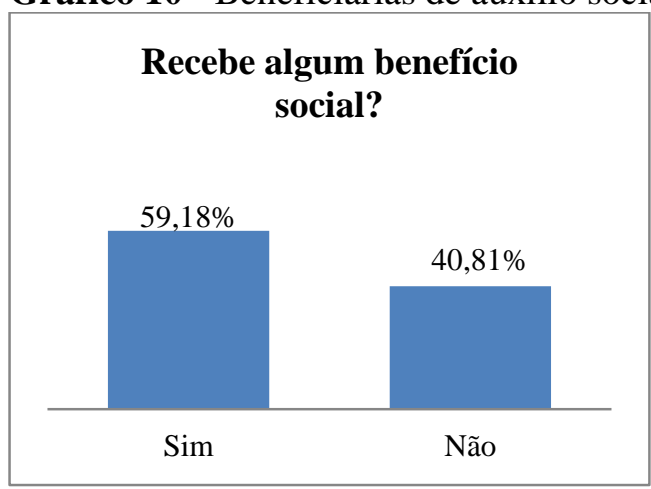

Fonte: Elaboração própria

Dados: CIAM
Gráfico 11 - Perfil moradia (\%)

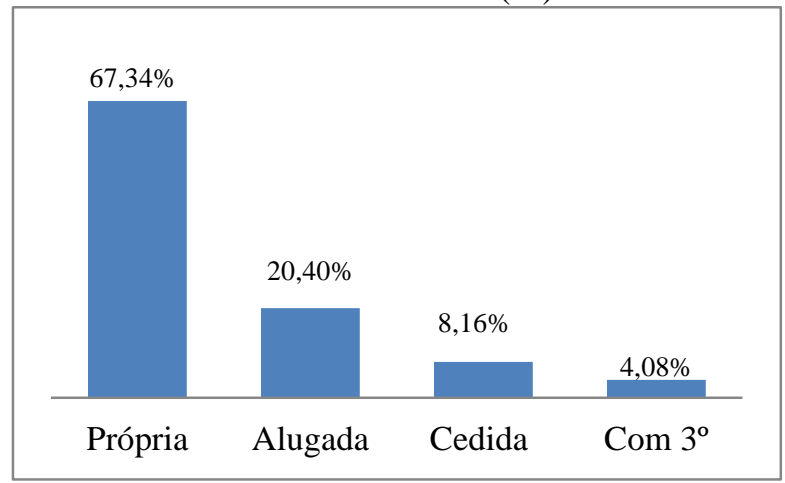

Fonte: Elaboração própria

Dados CIAM 
Gráfico 12 - Tempo de convivência (\%)

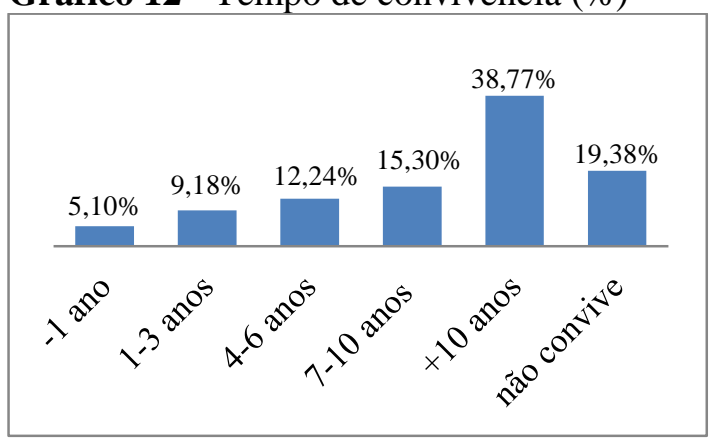

Fonte: Elaboração própria Dados: CIAM 2018
Gráfico 13 - Medida protetiva/queixa (\%)

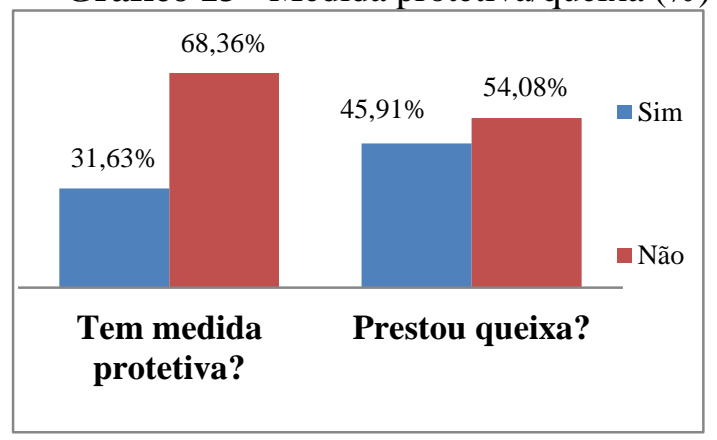

Fonte: Elaboração própria Dados: CIAM 2018

Depreende-se do exposto no Gráfico 6 que as mulheres católicas representam o percentual mais expressivo dentre as vitimadas, $51,02 \%$, seguidas pelas evangélicas, as que não possuem religião e as espíritas, estas com pouco menos de 2,04\%. Nota-se que os números estudados correspondem à realidade religiosa nacional, cujo catolicismo, segundo o IBGE em censo 2010, aparece como a mais professada religião no Brasil, com 64,6\%, seguida por evangélicos com $22,2 \%$. Espíritas, aparecem com $2 \%$; os sem religião contam com $8 \%$. Isso posto, observa-se que o dado encontrado no CIAM vem a se alinhar com os percentuais nacionais, não sendo razoável, por ele mesmo, ultimar que tal religião apresente-se como motivador das agressões, mas basicamente como reflexo de que existem mais pessoas católicas no país.

No que tange ao perfil profissional, Gráfico 7, 27,55\% das mulheres atendidas em 2018 declaram estarem desempregadas, sendo que $15,30 \%$ se reconheceram como "do lar". A análise dessas informações é imperiosa porque reverbera pertinente discussão acerca da manutenção da violência, introduzida neste trabalho ao mencionar a subnotificação. Pergunta-se: quais marcadores denunciam a permanência da mulher em situação de violência? O que impede a mulher de terminar um relacionamento abusivo?

Há uma tentativa, principalmente amparada no movimento feminista, de se desmistificar a máxima cruel de que mulher que permanece num relacionamento violento encontra prazer no sofrimento. Compreende-se que muitos fatores estruturais e, não só emocionais, atuam inviabilizando o rompimento desse ciclo. A falta de condições de subsistência e a carência de autonomia financeira, por exemplo, materializam-se fortemente nesse contexto. Na pesquisa em foco observou-se nos Gráfico 8, 9 e 10 que 50\% das mulheres tinham renda familiar entre um e dois salários mínimos, sendo o agressor o provedor da casa em 29,59\% dos casos. Nota-se ainda que 59,18\% eram beneficiárias de algum auxílio do governo, o que também se associa à vulnerabilidade social.

Importante destacar que alguns autores vêm defendendo com veemência a relação entre trabalho remunerado e intolerância à violência por parte das mulheres. Nessa acepção "[...] mulheres com trabalho remunerado e, por conseguinte, com contribuição para o orçamento familiar, possuem mais condições de não aceitarem a convivência agressiva e romper o ciclo violento" (MOTA; VASCONCELOS; ASSIS, 2007, p. 801-802).

Isso contribui para reflexão sobre a problemática envolvendo a violência doméstica contra mulher, chamando a atenção do Poder Público para criação e fortalecimento das redes de empoderamento, preparando-as para (re) inserção no mercado de trabalho, a fim de que o desemprego não sirva como veículo mantenedor do status de violência. O CIAM em Juazeiro, por sua vez, vem mobilizando ações emancipatórias voltadas à capacitação profissional, com oficinas diversas que intentam garantir às assistidas condições de superarem os impasses e se rotacionarem para um novo futuro.

Do perfil analisado no Gráfico 11, 64,37\% das vítimas afirmaram residir em casa própria, enquanto no Gráfico 12 38,77\% relataram conviver com o agressor por mais de 10 anos. Estes números podem inferir que o tempo de convivência atua como certo potencializador da violência 
contra parceira, pois traz para o agressor a sensação de segurança e possibilidade de permanecer no relacionamento mesmo depois de machucá-la. Posto isso, "a presença de filhos, o tempo de união entre vítima e agressor e o maior número de pessoas residentes no domicílio onde a mulher reside também são características associadas à violência conjugal" (MOTA; VASCONCELOS; ASSIS, 2007, p.800).

Nesse diapasão, evidenciou-se no Gráfico 13 que mais da metade das mulheres assistidas não requereram medida protetiva e nem prestaram queixa da violência. Depreende-se que mesmo nos dias atuais muitas ainda têm dificuldades para buscar os veículos legais na tentativa de denunciar o agressor ou garantir ferramentas de proteção. Esse dilema pode ser atribuído a múltiplos fatores que caminham no mesmo sentido da dificuldade de romper o ciclo violento, somado também ao temor pela própria vida e integridade. A isso se adiciona a ineficácia dos meios de proteção, que nem sempre cumprem seu papel, já que, mesmo dispondo de medida protetiva, diversas mulheres diariamente voltam a sofrer algum tipo de violência.

Segundo pesquisa realizada em 2015 pelo Observatório da Mulher Contra Violência, do Instituto Data Senado, duas em cada 10 mulheres agredidas não tomaram qualquer atitude em relação à agressão sofrida; $24 \%$ pela preocupação com a criação dos filhos; $21 \%$ por medo de vingança por parte do agressor; $16 \%$ porque acreditavam que seria a última agressão; $10 \%$ não acreditavam que ele seria punido; $7 \%$ sentiam-se envergonhadas pela agressão sofrida (A REAÇÃO..., 2015). Esses resultados clareiam acerca de alguns fatores em torno da decisão de não denunciar o agressor: questões afetivas ligadas à preservação da família, medo de retaliações, crença na mudança, ineficácia da justiça, baixa autoestima. Denota-se nesses dados a importância de enfrentar a problemática de modo holístico, considerando sua amplitude, a fim de viabilizar soluções mais passíveis de efetivação e transformação da realidade social.

Ademais, partindo da premissa de que a violência de gênero não é um fenômeno estanque e homogêneo que se apresenta uniformemente a todas as pessoas afetadas, buscou-se examinar as experiências referidas nas fichas de cadastro de mulheres que acessaram o CIAM em 2017 e 2018. Foram observadas cinco fichas em cada período, nas quais se prezou pela discussão dos dados não abrangidos nos demais registros primários, discutidos anteriormente.

Dessa análise, compulsando alguns dos resultados, concluiu-se que sete entre as 10 mulheres que sofreram algum tipo de violência a caracterizaram como "continuada", isto é, diferentemente da circunstancial, cuja ocorrência tende a ser mais isolada, as mulheres relataram que a agressão acontecia com certa frequência. Assim, muitas demonstraram dificuldades em romper com o ciclo de agressão, cinco delas evidenciando posteriormente que já haviam sido vítimas de algum tipo de violência e dentre os motivos que as fizeram permanecer no relacionamento, estão: filhos, acreditar na mudança, questões sentimentais e medo.

Além disso, seis delas disseram que a última violência ocorreu na própria residência. Enquanto seis foram vitimadas somente pelo companheiro, uma pelo companheiro, filhos e vizinho, duas pelo ex e uma somente pelo vizinho. Isso permite captar que o ambiente doméstico é palco de abuso porque "[...] a maioria das violências perpetradas contra mulheres é obra do (ex) marido, (ex) companheiro e (ex) namorado, a probabilidade de que ocorram no domicílio é altíssima" (SAFFIOTI,1995, p. 36), contribuindo para tese de que o lar, em vez de lugar de proteção, é palco de terror para grande parte das mulheres.

\subsection{EFETIVIDADE DAS POLÍTICAS PÚBLICAS}

No tocante ao tema proposto, mostra-se salutar promover reflexão acerca da pertinência e efetividade das políticas públicas voltadas à violência contra mulher, tendo como referência os dados dispostos no CIAM Juazeiro relativos à evolução de caso (assim intitulado pelo centro) no período de 2015 a julho de 2018. Estes correspondem ao quantitativo de mulheres que, outrora assistidas como vítimas de algum tipo de agressão, tornaram a padecer de violência.

Com efeito, buscou-se fixar um comparativo entre o total de registros em cada ano e a evolução de caso. Dessa forma, conforme ilustrado no Gráfico 14, evidenciou-se um percentual significativo de mulheres que retornaram ao centro em cada período. Em 2015, por exemplo, foram 281 casos registrados, sendo 33,8\% desses, evoluções. Por sua vez, em 2016 constata-se que $18 \%$ das mulheres foram novamente vitimadas, seguidos por $21,77 \%$ em 2017 e $14,78 \%$ em 2018. 
Gráfico 14 - Reincidência das assistidas

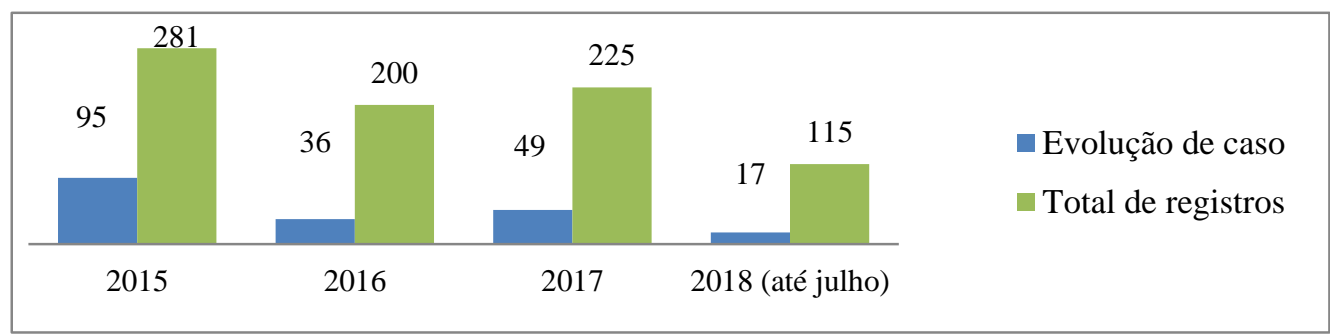

Fonte: Elaboração própria

Dados: CIAM 2015 a julho de 2018

Não obstante insuficientes para mensurar com exatidão a efetividade das políticas ligadas às mulheres no país, tais números fazem pensar em que medida os equipamentos voltados ao atendimento dessa demanda nutrem relação com a recidiva dos agressores. Problematiza-se em que medida esses números demonstram a falência do poder público em desenvolver meios efetivamente capazes de retirarem a mulher do ambiente agressivo e, garantirem que não sejam acometidas pelos mesmos fatos. Isso não apenas considerando a efetividade da DEAM, Rondas Maria da Penha e demais mecanismos repressivos, mas também dos veículos educativos que atuem não somente fortalecendo as mulheres a romperem relações abusivas, mas desconstituindo os discursos problemáticos envolvendo a subjugação do feminino.

Outrossim, a ausência de casas de proteção para receber mulheres em caráter emergencial potencializa o drama. Segundo dados do Perfil dos Municípios Brasileiros (MUNIC), em pesquisa realizada pelo IBGE (2018), o percentual de municípios com casas-abrigo no Brasil foi de apenas $2,4 \%$ em 2018. No caso de Juazeiro, somente em novembro de 2018 foi inaugurada a casa abrigo regional com a finalidade de acolher temporariamente mulheres ameaçadas pelo contato com agressor.

Nesse sentido, os números permitem refletir quanto à inviabilidade das políticas públicas no tocante ao processo de desconstrução dos padrões de gênero, sobretudo nas escolas. Assim, não é suficiente que essas mulheres serem assistidas com intento de remediar o problema se os meios preventivos não forem colocados em prática. Isso também deve ser analisado sob a ótica do agressor, aquele que pratica contra mulher a violência, a fim de promover reflexão acerca dos motivos que o levaram a cometer tais atos e as possíveis formas de transformação.

Soares (2012, p. 206), criticando a visão monolítica da violência conjugal, enfatiza a necessidade de trabalhar políticas que incluam o agressor, afirmando que:

[...] qualquer que seja a natureza da violência, se desejamos eliminá-la ou reduzi-la, é preciso, entre outras coisas, uma mudança de percepção de quem agride a respeito da pessoa ou de uma categoria de pessoas passíveis de serem agredidas. Em termos concretos, isso significa que é quando o perpetrador reformula a imagem que tem de uma determinada mulher ou das mulheres em geral, que a violência contra ela ou contra elas pode, finalmente, se tornar inconcebível. Porém, como é possível que os sujeitos envolvidos venham a transformar seu olhar sobre os outros e sobre si mesmos, fora do universo dialógico, no qual esse olhar se produz e se reproduz e em que se formam e se transformam as imagens e os papéis do masculino e do feminino?

Por conseguinte, somente atuando de maneira interdisciplinar e voltada aos diversos âmbitos será possível reconfigurar os padrões arquitetados sob a dominação pautada no gênero e alterar o contexto crescente de violência contra mulher no país.

\section{CONSIDERAÇÕES FINAIS}

Por fim, do anteriormente abordado, conclui-se que a violência contra mulher é um fenômeno bastante complexo que está em consonância com a hierarquia de gênero socialmente 
disposta. Esta, por sua vez, costuma relegar objetificação à figura feminina, atribuindo ao homem a livre disposição de seu corpo, inclusive legitimando a violência como forma de manutenção dessa supremacia.

Nessa vertente, buscou-se analisar a tipificação da violência a partir do perfil das assistidas, bem como, os fatores ligados à recidiva dos agressores. Mostra-se útil tal categorização na medida em que torna possível o desenvolvimento de políticas de enfrentamento mais consentâneas à realidade local, bem como, permite o fortalecimento da rede existente, com intervenções estratégicas no próprio CIAM.

Nesse diapasão, compreende-se a imprescindibilidade de garantir que essa problemática de gênero seja tratada de maneira holística, isto é, trazendo para discussão tanto a mulher em situação de violência quanto o agressor, a fim de promover uma real possibilidade de ressignificação de padrões arraigados e, potencialmente, transformação social. Desse modo, fazse mister a integralização de veículos que garantam a participação masculina, assim como, o debate em torno do ensino primário, remetendo à importância de uma atuação mais incisiva do Estado no tocante ao desenvolvimento e real implementação de políticas públicas voltadas a esse cenário.

Ademais, notou-se, de maneira positiva e contrariando a subnotificação e negligência por vezes constada nessa modalidade, que a violência psicológica foi a mais registrada no CIAM Juazeiro desde 2006. Isso permite pensar a tentativa de desnaturalização por parte das vítimas e o desenvolvimento, pelo Centro, de medidas mais pautadas à superação desse fato, tais como os grupos de escuta e empoderamento coletivo.

Em suma, nota-se a relevância de evocar o Poder Público para atuar diretamente sobre os aspectos delineados nessa pesquisa, de modo a contribuir para transformação do contexto social de violência evidenciado. Importa que o Estado transforme em ações integradas aquelas abstrações delineados em seu sistema jurídico, sobretudo no tocante ao arcabouço legislativo, por vezes insuscetível de viabilidade prática, a fim de responder mais satisfatoriamente às dinâmicas sociais.

Posto isso, cumpre observar que o presente estudo carece ainda de outros aprofundamentos, face às limitações metodológicas impostas, porém, em caráter introdutório pode atuar como alerta aos marcadores sociais específicos e contribuir para reconfiguração do contexto de violência contra mulher não só no município, mas a nível nacional.

\section{REFERÊNCIAS}

ALEMANY, Carme. Violências. In: HIRATA, Helena. ET. AL. Dicionário Crítico do Feminismo. São Paulo: UNESP, 2009, p. 271-276.

A REAÇÃO das Mulheres à Violência. Observatório da mulher contra violência, Senado Federal, Instituto DataSenado, 2015. Disponível em: https://www12.senado.leg.br/institucional/omv/entenda-a-violencia/a-reacao-das-mulheres-aviolencia. Acesso em: 22. abr. 2019.

BARbOSA, Anna Christina Freire. Lei Maria da Penha: Da convivência com as práticas do sistema de justiça no submédio do Vale do São Francisco. Tese (Doutorado em Ciências Sociais) - Universidade Federal do Rio Grande do Norte, Natal, 2014.

BOURDIEU, Pierre. A Dominação Masculina. Rio de Janeiro: Bertrand Brasil, 2002.

BRASIL. Lei ${ }^{\circ}$ 11.340, de 7 de agosto de 2006. Cria mecanismos para coibir a violência doméstica e familiar contra a mulher. Brasília, DF: Senado Federal, [2006]. Disponível em: http://www.planalto.gov.br/ccivil_03/_Ato2004-2006/2006/Lei/L11340.htm. Acesso em: 05 set. 2020. Acesso em: 05 set. 2020. 
BRITO, Débora. Denúncias de violência contra a mulher chegam a 73 mil em 2018. Atarde Uol, Agência Brasil, 07 de agosto de 2018. Disponível em:

http://atarde.uol.com.br/brasil/noticias/1983154-denuncias-de-violencia-contra-a-mulherchegam-a-73-mil-em-2018. Acesso em: 22. abr. 2019.

CERQUEIRA, D. ET AL. Atlas da violência 2018. Rio de Janeiro: Fórum Brasileiro de Segurança Pública, 2018. Disponível em:

https://www.ipea.gov.br/portal/index.php?option=com content\&id=33410. Acesso em: 05 set. 2020.

CÔRTES, G. R.; LUCIANO, M. C. F.; DIAS, K. C. O. A informação no enfrentamento à violência contra mulheres: Centro de Referência da Mulher Ednalva Bezerra: relato de experiência. Biblionline, João Pessoa, v. 8, n. esp. p.134-151, 2012. Disponível em: https://periodicos.ufpb.br/ojs2/index.php/biblio/article/view/14199. Acesso em: 05 set. 2020.

IBGE - INSTITUTO BRASILEIRO DE GEOGRAFIA E ESTATÍSTICA. Censo Demográfico 2010. IBGE, Censo 2010, 2010. Disponível em: https://censo2010.ibge.gov.br/noticiascenso.html?busca $=1 \& \mathrm{id}=3 \& \mathrm{idnoticia}=2170 \& \mathrm{t}=$ censo-2010-numero-catolicos-cai-aumentaevangelicos-espiritas-sem-religiao\&view=noticia. Acesso em: 22 abr. 2019.

IBGE - INSTITUTO BRASILEIRO DE GEOGRAFIA E ESTATÍSTICA. MUNIC: Perfil dos Municípios Brasileiros. Agência IBGE Notícias, 2019. Disponível em: https://agenciadenoticias.ibge.gov.br/agencia-noticias/2012-agencia-de-noticias/noticias/25518mesmo-com-lei-maria-da-penha-somente-2-4-dos-municipios-oferecem-casas-abrigo. Acesso em: 27 fev. 2020.

MOTA, J. C; VASCONCELOS, A. G. G.; ASSIS, S. G. de. Análise de correspondência como estratégia para descrição do perfil da mulher vítima do parceiro atendida em serviço especializado. Ciência e Saúde coletiva, 12(3), p. 199-809, 2007. Disponível em: https://www.scielosp.org/article/csc/2007.v12n3/799-809/. Acesso em: 05 set. 2020.

NÚMERO de feminicídios cresce $6 \%$ na Bahia em 2018, crimes violentos tem redução de 11,5\%. Portal G1, Bahia, 27 de dezembro de 2018. Disponível em: https://g1.globo.com/ba/bahia/noticia/2018/12/27/numero-de-feminicidios-cresce-6-na-bahiaem-2018-crimes-violentos-tem-reducao-de-115.ghtml. Acesso em: 22 abr. 2019.

SAFFIOTI, Heleieth Iara Bongiovani. Violência de gênero: Poder e Impotência. Rio de Janeiro: Revinter, 1995.

SILVA, L.L; COELHO, E. B. S.; CAPONI, S. N. C. de. Violência silenciosa: violência psicológica como condição da violência física. Interface Comunic., Saúde, Educ., v.11, n.21, p.93-103, jan/abr. 2007. Disponível em: https://www.scielo.br/scielo.php?pid=S1414-

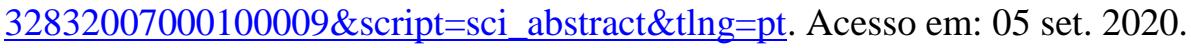

SOARES, Barbara Musumeci. A 'conflitualidade' conjugal e o paradigma da violência contra a mulher. Dilemas, Rev. Estud. Conflito Controle Soc., Rio de Janeiro, vol. 5, n. 2, pp. 191210, 2012. Disponível em: https://revistas.ufrj.br/index.php/dilemas/article/view/7326. Acesso em: 05 set. 2020.

TODOS os dias 32 mulheres são vítimas de violência em Salvador. Correio 24 horas, Bahia, 09 de abril de 2019. Disponível em: https://www.correio24horas.com.br/noticia/nid/todos-osdias-32-mulheres-sao-vitimas-de-violencia-em-salvador/. Acesso em: 02. maio. 2019.

WAISELFISZ, Julio Jacobo. Mapa da violência 2015: Homicídio de mulheres no Brasil. Brasília: Flacso Brasil, 2015. Disponível em: http://flacso.org.br/?publication=mapa-daviolencia-2015-homicidio-de-mulheres-no-brasil. Acesso em: 05 set. 2020. 


\section{AGRADECIMENTOS}

Agradecemos à equipe do Centro Integrado de Atendimento à Mulher de Juazeiro/BA pela disponibilidade de dados e colaboração com a realização da pesquisa, bem como, ao Programa de Iniciação Científica da Universidade do Estado da Bahia (UNEB), por viabilizar a realização deste trabalho. 